\title{
Urology-Related Conditions Should Not Be Overlooked in Women with Polycystic Ovary Syndrome
}

\author{
Tariq Faisal Al-Shaiji ${ }^{10}$ \\ ${ }^{1}$ Urology Unit, Department of Surgery, Jaber Al-Ahmad Al-Jaber Al- \\ Sabah Hospital, Kuwait City, Kuwait
}

Rev Bras Ginecol Obstet 2021;43(10):793.

Dear Editor,

It has been documented that women with polycystic ovary syndrome (PCOS) may suffer from sequelae that can surpass the obstetrics and gynecology armamentarium. For example, Shah and Rasool ${ }^{1}$ gathered data from the literature showing clear evidence that PCOS is associated with an increased risk of developing type-2 diabetes mellitus, hypertension, dyslipidemia, endometrial cancer, and subclinical atherosclerosis. Therefore, screening for these disorders at the initial contact with these patients, as well as periodically, is recommended.

The findings reflecting the extent of the PCOS sequelae are intriguing. Nevertheless, I would like to highlight some points. We should look further beyond when it comes to PCOS and other associated diseases. The syndrome has been specifically implicated in a few urological conditions as well. In 1988, Fowler et al. ${ }^{2}$ first described Fowler syndrome in young women with unexplained complete urinary retention with a unique abnormal pattern of electromyographic (EMG) activity and clinical features of PCOS. They suggested that the abnormal EMG activity was driven by a relative deficiency of progesterone leading to impairment of the urinary sphincter relaxation. ${ }^{2}$ Meanwhile, other authors ${ }^{3}$ have speculated that hyperoestrogenemia in PCOS might impair the relaxation of the urethral sphincter, leading to urinary retention. It is believed that PCOS in women with Fowler syndrome occurs in $~ 64 \%$ of the cases. ${ }^{4}$ Furthermore, It has been hypothesized that PCOS may lead to urolithiasis by triggering stone formation in the urinary tract. ${ }^{5}$
Address for correspondence Tariq Faisal Al-Shaiji, MB. ChB., FRCSC, Urology Unit, Department of Surgery, Jaber Al-Ahmad Al-Jaber Al-Sabah Hospital, P.O. Box 34489, Adelliah, Kuwait City, Al-Asima 73255, Kuwait (e-mail: tshaiji@gmail.com).

Therefore, given that PCOS and these urological issues seem to be correlated, it is advised that women treated for one condition be screened for the other condition and vice versa. I hope that the aforementioned facts can add to the general awareness for women with PCOS and widen the circle of clinical assessment for these patients.

\section{Conflict of Interests}

The author has no conflict of interests to declare.

\section{References}

1 Shah D, Rasool S. Polycystic Ovary Syndrome (PCOS) transition at menopause. J Midlife Health. 2021;12(01):30-32. Doi: 10.4103/ jmh.jmh_37_21

2 Fowler CJ, Christmas TJ, Chapple CR, Parkhouse HF, Kirby RS, Jacobs HS. Abnormal electromyographic activity of the urethral sphincter, voiding dysfunction, and polycystic ovaries: a new syndrome? BMJ. 1988;297(6661):1436-1438. Doi: 10.1136/ bmj.297.6661.1436

3 Shin JI. Fowler's syndrome-progesterone deficiency or oestrogen excess? Nat Rev Urol. 2014;11(10):553. Doi: 10.1038/ nrurol.2013.277-c1

4 Swinn MJ, Wiseman OJ, Lowe E, Fowler CJ. The cause and natural history of isolated urinary retention in young women. J Urol. 2002;167(01):151-156

5 Kaygusuz I, Karatas OF, Kafali H, Cimentepe E, Unal D. Is polycystic ovarian syndrome a risk factor for urolithiasis? Urolithiasis. 2013; 41(04):361-362. Doi: 10.1007/s00240-013-0564-9 received

May 30, 2021

accepted

August 31, 2021
DOI https://doi.org/

10.1055/s-0041-1736552. ISSN 0100-7203. (c) 2021. Federação Brasileira de Ginecologia e Obstetrícia. All rights reserved.

This is an open access article published by Thieme under the terms of the Creative Commons Attribution License, permitting unrestricted use, distribution, and reproduction so long as the original work is properly cited. (https://creativecommons.org/licenses/by/4.0/)

Thieme Revinter Publicações Ltda., Rua do Matoso 170, Rio de Janeiro, RJ, CEP 20270-135, Brazil 